\title{
The Effect of a Nature-friendly Integration Program on Self-esteem and Depression of the Elderly in Nursing Home Residents
}

\author{
Chang Mi Kim and Geo Lyong Lee* \\ Department of Natural Theraphy, Graduate School of Integrative Medicine, Sunmoon University, Asan 31140, South Korea
}

\begin{abstract}
The life expectancy of human beings has been extended, and the transition from aging to aging is accelerating. This rapid increase in aging has made health problems of the elderly more important. The health problems of elderly people are burdened with social and economic burden. Along with the physical change of the elderly, the psychological stability and mental health measures of the elderly should be emphasized and adequate and sustainable social support for the elderly should be provided. A healthy lifestyle is an important factor that had been better in the elderly with a lively social relations determine these social links are physical activity, the ability of the elderly. Elderly people living in the facility tend to be depressed or self-esteemed by mental anxiety due to the transfer from the family to the facility. Therefore, we need a program to improve the self - esteem and depression of the elderly. If a non-single, self-integration program is provided to the elderly, the integration program consisting of nature-friendly contents will be familiar to the elderly and participation will increase. The program with the play is effective because it can give pleasure and laughter, and the nature-friendly integration program is applied. A natural-friendly integration program is an integration program of integrated forest healing, horticultural therapy, and play, based on an earlier paper on the effects of forest healing and plant-mediated horticultural therapy, Respectively.
\end{abstract}

Key words: forest healing, horticultural therapy, integration program, nature friendly

\section{I . Introduction}

As the average life span of human being has been extended due to development of medical technology and rapid economic growth, the era of ageing population has been rapidly changed to that of aged population. As of 2015, the number of people over age 65 account for $13.2 \%$ of the entire population, 6.659 million, which means the elderly is $11.8 \%$ of the population. This will increase to $15.7 \%$ by 2020 and to $24.3 \%$ by 2030 according to National Statistical Office $(2013,2016)$. Likewise, this rapid increase of aged population has come with serious health issues of the elderly. Though anyone can understand that the health problems of the elderly can be a huge social and economic burden over the society, there has been no precise measures to curb it yet so far. Along with the physical change of the elderly, the psychological health is observed to have been deteriorated, which definitely needs corresponding social support.

Received on May 11, 2017. Revised on May 27, 2017.

Accepted on June 16, 2017.

*Corresponding author: leeashram@hanmail.net
There should be a systematic study on socio-demographic and socio-psychological factors related to life satisfaction of the elderly and in particular correlation between life satisfaction, social support, depression, leisure activities and functional abilities should be defined and in-depth study on determinants of the life satisfaction is required, as some pointed out (Huh and Choi, 2011). When an elderly with active social relationship has a healthier life style and this social connection and information searches are important factors to determine the physical ability of the elderly (Bosworth and Schaie, 1997).

With introduction of the long-term care insurance for the elderly since 2008 , the number of the seniors entering the facilities has been rapidly increased. These elderly tend to be depressed or have lower self-esteem with mental anxiety caused by the transfer from the home with their family to the facility. As for the elderly, most of them do not want any change in their living environment, do not feel easy to adapt themselves to a new environment, which turns out it is desirable for them to live with their family (Park et al., 2007). Regardless of the reason for entry to the facility - whether it is 
an unavoidable choice due to health, economic or family issues or a choice for higher quality of nursing - The elderly at the facility have right to maintain their human dignity and satisfactory life at the same time their family, staff members of the facility and the society have responsibility to support their happy life (Moon, 2016). These elderly at the facility may end up with unhealthy mind and body due to disconnected social activities, psychological anxiety and negative impacts on their comfortable survival (Mirotznik and Kamp, 2000).

In addition, leaving their family and staying at this facility can add more burden on their self-esteem and depression (Kim, 2010). Therefore, these elderly need programs to improve their self-esteem and depression. However, as we observed the studies done on the elderly so far, single program showed effectiveness while the study by Woods et al., in 2009 showed since each single program such as music, art therapy, physical activities etc., was studied, diversity of an individual elderly at the facility in terms of their life, experience, environment, physical characteristics and psychological world was not able to be accommodated in a holistic way, it failed to approach geriatric illness. Kim (2010) observed that since dementia requires multifaceted approach since the disease impairs cognitive and physical functions comprehensively, short-term or single program cannot make bigger impact on prevention. In case of single program for short-term, program participation differs depending on individual interest and has impact on effectiveness of application. integration program can arouse interest of the subject so that he or she can actively participate in the ongoing program and in particular the integration program proceeded with consecutively can improve declining functions of the elderly (Jang, 2007). Likewise, we need an integration program targeting the elderly and if nature-friendly integration program not a single program is implemented on the elderly at the facility, it can increase the interest and participation, which will in turn make a better result. Nature-friendly integration program combines forest healing, horticultural therapy and play on the basis of the advanced paper on healing effects in a forest and effectiveness of horticultural therapy using plants as medium.

The purpose of this study is to implement not a single program but a nature-friendly integration program targeting the elderly at the facility and verify its effectiveness on self-esteem and depression and differences of self regulation quotient of brain wave and anti-stress quotient.

\section{Study Subject and Method}

\section{Study Subject}

We implemented this study after obtaining consent from elderly and their family among the 20 elderly at Facility Y, who received program participation presentation, have no difficulty in activities and no history of medication and expressed intention of participation. We selected the participants who have slight physical disability and the age of elderly is early 70 s. We explained about nature-friendly program and the design of experiment is pre-and post inspection of cohorts. This is an experiment to compare change in depression and self-esteem among the elderly at the facility and in order to verify the effectiveness of the program, we checked questionnaire and brainwave test before and after the experiment. Starting from August in 2016, this was implemented twice a week and 12 times for six weeks.

\section{Nature-Friendly integration program Make-up}

This program was named nature-friendly integration program, combining forest healing, horticultural therapy and play therapy. Six major therapies of forest healing - phytotherapy, water therapy, alimentotherapy, terrain therapy, mental therapy, climatherapy) were composed according to each subject and horticultural therapy was made up of transplanting, observation, breeding sprout, aquaculture, etc., whose effectiveness were studied for improving depression and self-esteem. Forest play is a program to ensure participation of subjects, made up of programs which require fun and the spirit of teamwork. The programs are as followed in Table 1.

\section{Measuring tools and Statistics Process}

\section{1) Depression}

The tool of measuring depression is what Kim (1985) translated BDI tools developed by Beck et al. (1961), made up of 21 questions including those about emotional, cognitive, motivational and physiological syndromes after modification 
Table 1. Nature-friendly integration programs.

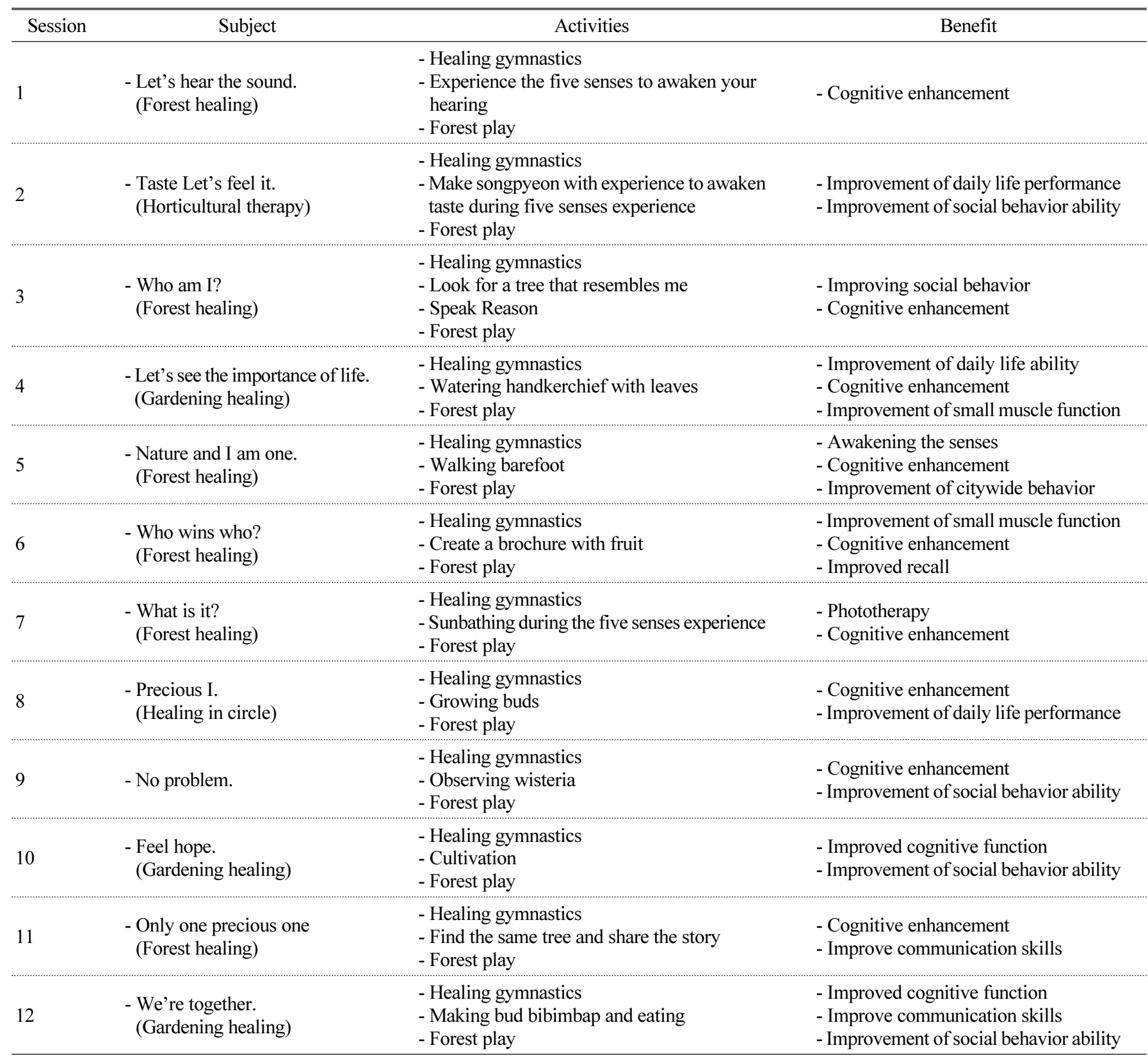

and complementation. This tool has scale of 4 points from 0 to 3 and score ranges from 0 to 63 . The higher the score is, the more serious the depression goes. In this study, if the score is below 9 points, you are in no-depression group, from 10 to 15 is light depression group, 16-23 is severe depression and 24-63 is serious depression.

\section{2) Self-Esteem}

Measuring tool for self-esteem is modified and complemented tools into which Jon (1974) translated what Rosenberg (1965) developed. It is made up of five positive question and five negative questions. Answers from negative questions are calculated back and combined with answers to positive questions. The scale of score is $10 \sim 50$ and the higher the score is, the higher your self-esteem is. 


\section{3) Brain wave test}

Brain wave testing tool is to measure brain wave by using two channel system mobile BCI (Neuro-Harmony, Braintech Co.) in order to analyze self regulation quotient and anti-stress quotient. Anti-stress quotient is to indicate the resistance to stress. Accordingly, it can be used as indicator of expressing physical and mental degree of fatigue caused by internal and external environmental factors. As mental stress refers to psychological tension, anxiety and excited condition, the higher your anti-stress quotient is, the higher degree of fatigue you have, which means you have less immune to diseases. Conversely, if you have lower anti-stress quotient, you are highly resistant to diseases (Peniston and Kulkosky, 1989; 1990; 1991; 1992).

\section{4) Statistics Process}

The data collected for this study was studied and analyzed by undergoing data-coding process for statistics process and using SPSS (Statistical Package for Social Science) V22.0, a statistics package program. In order to verify the differences between depression and self-esteem of before and after program execution, we used matching sample t-verification method for analysis. For all the data, we calculated the average and standard deviation. The statistical level of significance of data was set to ${ }^{*} p<.05,{ }^{* *} p<.01,{ }^{* * *} p<.001$ by paired t-test.

\section{Result and Consideration}

\section{Analysis on Depression}

Table 2 is the analysis result of corresponding sample t-verification for depression index. The average score for pre-test and post-test were 48.70 and 17.60 while $t=-25.99$ and $p=.000$ have meaningful differences. As a domestic study for psychological effect of forest healing, subjects who participated

Table 2. Depression index analysis result.

\begin{tabular}{|c|c|c|c|c|c|c|}
\hline & & $\mathrm{N}$ & $M$ & $S D$ & $t$ & $p$ \\
\hline \multirow{2}{*}{ Emotion } & Before & 20 & 48.70 & 6.19 & \multirow{2}{*}{25.998} & \multirow{2}{*}{$.000^{* * *}$} \\
\hline & After & 20 & 17.60 & 1.23 & & \\
\hline
\end{tabular}

$* * * p<.001$ by paired t-test. various programs such as group discussion, emotion sharing, etc., were subject to measuring Beck Depression Inventory, depression index before and after the program and as a result it was consistent with the study result that forest program is effective in alleviating depression (Shin et al., 2000). We were able to get the same result with Lim et al. (2008) that horticulture therapy is effective in reducing depression of the elderly since it gives positive sentiment to revive human's naturefriendly instinct.

\section{Analysis of Self-esteem}

Table 3 is the corresponding sample t-verification analysis on the self-esteem index. The average scores of pre- and post-test are 16.70 and 40.85 respectively with $\mathrm{t}=-27.71$ and $p=.000$, which are meaningful differences. This is also consistent with the result of Choi and Lim (2015) that horticulture therapy is highly likely to have significance on psychological and emotional area including self-respect, emotion stability and depression. It is also in line with the study of Yu and Jeong (2010) that horticulture therapy programs are effective to improve depression, enhance self-esteem and help the elderly to make positive changes at the facility in horticulture activity evaluation.

\section{Brain wave Analysis Result}

Table 4 is the analysis result of corresponding sample $\mathrm{t}$-verification analysis on self regulation quotient. The average scores of pre- and post-test are 55.11 and 76.16 respectively

Table 3. Self-esteem index analysis result.

\begin{tabular}{|c|c|c|c|c|c|c|}
\hline & & $\mathrm{N}$ & $M$ & $S D$ & $t$ & $p$ \\
\hline \multirow{2}{*}{ Self-esteem } & Before & 20 & 16.70 & 2.66 & \multirow{2}{*}{-27.714} & \multirow{2}{*}{$.000 * * *$} \\
\hline & After & 20 & 40.85 & 3.12 & & \\
\hline
\end{tabular}

$* * * p<.001$ by paired t-test.

Table 4. Self-regulation index analysis result.

\begin{tabular}{|c|c|c|c|c|c|c|}
\hline & & $\mathrm{N}$ & $M$ & $S D$ & $t$ & $p$ \\
\hline \multirow{2}{*}{ Self-regulation } & Before & 20 & 55.11 & 18.89 & \multirow{2}{*}{-2.874} & \multirow{2}{*}{$.010^{*}$} \\
\hline & After & 20 & 76.16 & 27.31 & & \\
\hline
\end{tabular}

$*_{p}<.05$ by paired t-test. 
with $\mathrm{t}=-2.87$ and $p=.010$, which have significant differences. These results suggest that self - control ability is improved by decreasing depression and increasing self - esteem.

Table 5 is the analysis result of corresponding sample t-verification on anti-stress index (left brain). The average scores of pre- and post-test are 73.98 and 85.35 respectively with $\mathrm{t}=-4.02$ and $p=.001$, which have significant differences.

Table 6 is the analysis result of corresponding sample $\mathrm{t}$-verification on anti-stress index (right brain). The average scores of pre- and post-test are 67.98 and 82.55 respectively with $\mathrm{t}=-3.499$, and $p=.002$, which have significant differences. Meditation, one of the nature-friendly integration programs is reported to have alleviated pains of those with chronic illnesses and have mitigated medical and psychological symptoms (Baer, 2003; Chiesa and Serretti, 2009) as well as to have been effective in treating stress-related illnesses according to the accumulative scientific evidence (Greeson, 2009). It is also consistent with the previous study that nature-friendly integration programs are effective in alleviating stress.

During the senescence, it is important to manage physical illness and stress from daily life. In particular, the elderly at the facility may feel isolated after departing from their family and tend to feel depression and declining self-esteem. As they get older, lower self-esteem can be developed into serious psychological conditions such as depression. Study of Min et al. (2002) shows that the higher your self-esteem is, the lower your depression level is. Younger ages than older ages, higher education with spouses alive have higher self-esteem. According to the study of Kim (2001), higher the self-esteem is, the lower

Table 5. Antistress index (left brain) analysis result.

\begin{tabular}{lcccccc}
\hline & & $\mathrm{N}$ & $M$ & $S D$ & $t$ & $p$ \\
\hline $\begin{array}{l}\text { Antistress } \\
\text { (Left brain) }\end{array}$ & Before & 20 & 73.98 & 10.19 & & \\
\cline { 3 - 6 } & After & 20 & 85.35 & 8.94 & -4.016 & $.001^{* *}$ \\
\hline
\end{tabular}

$* * p<.01$ by paired t-test.

Table 6. Antistress index (Right Brain) analysis result.

\begin{tabular}{|c|c|c|c|c|c|c|}
\hline & & $\mathrm{N}$ & $M$ & $S D$ & $t$ & $p$ \\
\hline \multirow{2}{*}{$\begin{array}{l}\text { Antistress } \\
\text { (Right brain) }\end{array}$} & Before & 20 & 67.98 & 17.13 & \multirow{2}{*}{-3.499} & \multirow{2}{*}{$.002 * *$} \\
\hline & After & 20 & 82.55 & 9.90 & & \\
\hline
\end{tabular}

$* * p<.01$ by paired t-test. the depression level is and the better your financial situation, the healthier, the more satisfactory with your allowances, you have higher self-esteem. If the group that participate in the program can maintain continuous participation for 12 weeks, stress resistance among brain's functional quotients improves, based on which other brain functional quotients can have positive effects. This is also consistent with the study result of Sim and Ko (2009).

As studied in the previous papers, the study of Sung et al. (1995). which worked on correlation between depression and self-esteem also showed that the elderly with higher self-esteem have more satisfaction with their life since they have less stress. Therefore this paper was to study on whether the elderly at the facility can have changes in depression, self-esteem, anti-stress and self-regulation and to compose nature-friendly integration program to verify the effectiveness of the program.

The program was named nature-friendly integration program implemented on the elderly at the facility, made up of forest healing, horticulture therapy and play therapy which prove effective in the previous papers. We implemented body recognition gymnastics, a total of 12 times, twice a week for six weeks and conducted forest healing and horticulture therapy alternately along with the play program executed every session. These elderly had no sense of rejection about and highly participated in forest healing, horticulture therapy and play therapy since theses reminded them of their past. They waited for each session and those with insufficient past experience felt sorry that they had not have tried before.

The number of the subjects at the facility was 20 with slight physical difficulty and no major handicaps and the average age was 75 which were subject to questionnaire and brain function test, which allowed us to obtain significant outcome. As studied in the previous papers, we were able to see the correlations between self-esteem, depression, self-regulation quotient and anti-stress index, which is considered a significant result.

\section{Conclusion}

Through this study, we observe how the elderly have changes in reaching life satisfaction after entering the facility through nature-friendly integration program - forest healing, horticulture 
therapy and play therapy - which have impact on self-esteem and depression. Through this, we are intended to complement any shortcomings of each individual program concerning life satisfaction of the elderly at the facility and make small activities become daily by integrating each programs connections in a nature-friendly way. When they experience nature with their five senses, use their physical functions through forest play and grow plants in person through horticulture therapy, they turn themselves from those receiving care to those giving care to nature and can establish themselves as an independent and self-esteemed entity, which is considered to offset depression, we believe. This nature-friendly integration program is meaningful in that it laid the foundation for us to recognize the necessity to study integrated program that considers diversity of the elderly in comparison with a single program. However, the study failed to exclude the possibility that the subject may recompose their perception about the situation before entry to the facility due to the experience after entry. Accordingly, we need to conduct a study with longitudinal design starting from the point they consider the entry to the facility so that we can identify causal relation between the reason for entry and life satisfaction in post-entry. In addition, this study has its own limitation in generalizing the study result since it utilized intentional sampling method for collecting data. Depending on gender, facility size and cognitive functions, there are differences in life satisfaction of the elderly. Therefore, there should be repetitive studies targeting various samples in the follow-up studies.

\section{References}

Baer, R.A. 2003. Mindfulness training as a clinical intervention: A conceptual and empirical review. Clin. Psychol.: Sci. Pract. 10(2): 125-143. DOI: 10.1093/clipsy.bpg015

Beck, A.T., C.H. Ward, M. Mendelson, J. Mock, and J. Erbaugh. 1961. An inventory for measuring depression. Arch. Gen. Psychiatry 4(6):561-571. DOI: 10.1001/archpsyc.1961.01710120031004

Bosworth, H.B. and K.W. Schaie. 1997. The relationship of social environment, social networks, and health outcomes in the Seattle longitudinal study: Two analytical approaches. J. Gerontol. Series B: Psychol. Sci. Soc. Sci. 52(5):197-205. DOI: 10.1093/geronb/ 52B.5.P197

Chiesa, A. and A. Serretti. 2009. Mindfulness-based stress reduction for stress management in healthy people: A review and meta- analysis. J. Altern. Complement. Med. 15(5):593-600. DOI: 10.1089/acm.2008.0495

Greeson, J.M. 2009. Mindfulness research update: 2008. Complement. Health Pract. Rev. 14(1):10-18.

Huh, J.S. and W.H. Choi. 2011. Periodic exercise and psychological well-being among the elderly persons. Korean J. Public Health 48(1):1-11.

Jang, S.H. 2007. A study on the effect of dementia prevention program. PhD Diss., Chosun Univ., Gwangju, Korea.

Jon, B.J. 1974. Self-esteem: A test of its measurability. Yonsei Article 11(1):107-130.

Kim, M.I. 2010. A study on the moderating effect of social support on the relationship between the elder abuse and the elderly depression. MS thesis, Donga Univ., Busan, Korea.

Kim, Y. 1985. Attributional model of depression. Inje Med. J. 6(3): 449-477.

Kim. D.H. 2001. A study on the correlation among family support, self-esteem and depression in ederly. Gerontol. Soc. Welf. Stud. 13:113-144.

Lim, H.J., Kim, K.H., and J.H. Kim. 2008. The effects of horticultural therapy on the depression, interpersonal relationships, and ADL of elderly people living in facilities. J. Welf. Aged 40:125-146.

Lim, J.S. and M.H. Choi. 2015. The effect of the leisure attitudes of the elderly on health promoting behavior and quality of life. Korean J. Leis. Recreat. Park 39(4):1-10.

Min, S., A. Ju, and H.H. Park, 2002. Practice of the elderly educational program for health improvement of the elderly. Gerontol. Soc. Welf. Stud. 17:11-236.

Mirotznik, J. and L.L. Kamp, 2000. Cognitive status and relocation stress: A test of the vulnerability hypothesis. The Gerontologist 40(5):531-539. DOI: $10.1093 /$ geront/40.5.531

Moon, J.H. 2016. Relocation situational factors and life satisfaction of the elderly in long-term care facilities: mediation effects of sense of control. J. Soc. Sci. Res. 42(1):229-256. DOI: 10.15820/ khjss.2016.42.1.010

National Statistical Office. 2013. 2013 elderly people statistics. Retrieved from http://kostat.go.kr/

National Statistical Office. 2016. 2016 elderly people statistics. Retrieved from http://kostat.go.kr/

Park, G.J., J.H. Lee, Y.H. Kang, and H.S. 2007. Self-esteem and depression of elders in welfare facilities. J. Gerontol. Nurs. 9(1): 51-59.

Peniston, E.G. and P.J. Kulkosky. 1989. Alpha-theta brain wave training and beta endorphin levels in alcoholics. Alcohol.: Clin. Exp. Res. 13(2):271-279. DOI: 10.1111/j.1530-0277.1989.tb00325.x

Peniston, E.G. and P.J. Kulkosky. 1990. Alcoholic personality and alpha-theta brain wave training. Med. Psychother. 3:37-55.

Peniston, E.G. and P.J. Kulkosky. 1991. Alpha-theta brain wave neurofeedback therapy for Vietnam veterans with combat-related posttraumatic stress disorder. Med. Psychother. 4(1):47-60.

Peniston, E.G. and P.J. Kulkosky. 1992. Alpha-theta EEG biofeedback training in alcoholism and posttraumatic stress disorder. Int. Soc. Study Subtle Energies Energy Med. 2:5-7. 
Rosenberg, M. 1965. Society and adolescent self-image. Vol. 11, p. 326. Princeton, NJ: Princeton Univ. Press USA.

Shin, W.S., S.I. Lee, J.H. Ryu, and E.W. Lee. 2000. The influence of forest experience on the mental health. J. Korean Inst. For. Recreat. 4(2):25-32.

Shim, J.Y. and B.J. Ko. 2009. Effects of brain development program for improving self-regulation and concentration in youth. Korean J. Youth Stud. 16(9):1-29.

Suh, M.K. and J.S. Kim. 1995. An analysis of life satisfaction determinants among elderly persons in Korea. Health Soc. Welf. Rev. 15(2):40-59.

Woods, B., A.E. Spector, C.A. Jones, M. Orrell, and S.P. Davies. 2009. Reminiscence therapy for dementia. Cochrane Database of Systematic Review 2005(2). DOI: 10.1002/14651858.CD001120. pub2.

Yu, Y.K. and H.Y. Jeong. 2010. Effect of horticultural therapy program on the depression and self-esteem of the older adult in facilities. Korean J. Soc. People Plant Environ. 13(3):7-15. 